\title{
Research on the Communication Strategy of Region of Rivers and Lakes Tourism Brand in China
}

\author{
Yuting $\mathrm{Li}^{1, *}$ Baoer $\mathrm{Yi}^{1}$ \\ ${ }^{1}$ School of Art and Design, Guangdong University of Finance \& Economics, Guangzhou, Guangdong, China \\ *Corresponding author. Email: Yuting_Li@gdufe.edu.cn
}

\begin{abstract}
Lingnan region of rivers and lakes is the birthplace of regional culture and the carrier of historical information. It has ushered in new changes and new trends in the process of rural revitalization and urbanization. How to balance economic development and protection of region of rivers and lakes has become a problem that has to be faced in the process of modernization of region of rivers and lakes. Based on this background, this article chooses China's Gulao region of rivers and lakes as the research object, and based on the important role of brand building, it studies the current situation and optimization strategies of the cultural tourism brand of Lingnan region of rivers and lakes.
\end{abstract}

Keywords: Brand communication, Cultural tourism brand, Lingnan region of rivers and lakes.

\section{INTRODUCTION}

The China Brand Building Power Strategic Alliance established a series of brand activities and aroused the attention and support of the whole society for brand building and communication. Gulao region of rivers and lakes, Heshan City, Guangdong Province, has the largest and bestpreserved mulberry fish pond style in the Lingnan area [1]. It has superior ecological resources and profound historical and cultural heritage. It is a typical representative of Lingnan region of rivers and lakes. In 2019, OCT (Overseas Chinese Town) Group took over the operation of Gulao region of rivers and lakes and started to build the "China Gulao" cultural tourism brand project, which was included in the key construction project of Guangdong Province in 2020.

*Project: This article is the research result of the 2020 Guangdong Province Degree and Graduate Education Reform Research Project "Research on the Construction Management System and Mechanism of the Joint Training Postgraduate Demonstration Base Based on Process Control" (2020JGXM052).

\section{THE IMPORTANCE OF CULTURAL TOURISM BRAND COMMUNICATION TO THE DEVELOPMENT OF LINGNAN REGION OF RIVERS AND LAKES}

According to the definition of the American Marketing Association, a brand is a "name, proper noun, mark, symbol, or design, or a combination of the above elements, used to identify the goods and services of a seller or group of sellers, and make them distinguish from competitors' goods and services" [2]. Cultural tourism brands can integrate the cultural resources of Lingnan region of rivers and lakes, strengthen regional characteristics, and extend regional cultural values and economic benefits. Brand communication is the main means of brand marketing. It is not only the process of inheriting the culture of the region of rivers and lakes, but also the process of shaping the image of the region of rivers and lakes and accumulating assets. It plays an important role in cultivating consumer loyalty and enhancing the regional cultural competitiveness of the region of rivers and lakes. 


\section{THE STATUS QUO AND PROBLEMS OF CULTURAL TOURISM BRAND COMMUNICATION IN GULAO REGION OF RIVERS AND LAKES}

\subsection{Brand Awareness Has Increased, and Brand Positioning and Communication Purpose Have Been Gradually Clarified}

Before July 2019, the brand communication strategy of "selecting the audience according to the media" reflected in the advertising activities of Gulao region of rivers and lakes showed that its brand positioning was vague, lacking macro-control and differentiated positioning. Vague brand positioning has led to the failure of Gulao region of rivers and lakes to form a unified media image on different platforms. Media resources cannot be relatively concentrated in the information dissemination of a certain target consumer group, so that consumers' interpretation and memory of the brand of the Gulao region of rivers and lakes in the process of tourism brand selection are blurred, and there is a deviation between the communication effect and the expected target.

After the OCT Group took over the operation of Gulao region of rivers and lakes, it adopted the model of "cultural tourism + beautiful countryside", with "free flowing life of region of rivers and lakes" as the main theme [3], and made Gulao region of rivers and lakes be built into China's most beautiful Lingnan region of rivers and lakes and a cultural and ecological tourism resort benchmark in the Guangdong-Hong Kong-Macao Greater Bay Area, and its brand positioning has gradually become clear.

\subsection{The Brand Communication Platform Is Scattered and Mostly Uses Regional Media, and the Brand Awareness Is Strongly Restricted by the Region}

Judging from the geographical distribution of people searching for keywords on search engines, most of the users who follow the information of Gulao region of rivers and lakes come from Guangdong Province. In the survey of audience perception and attitudes [4], 41\% of the respondents from Guangdong Province have never heard of the cultural tourism brand of Gulao region of rivers and lakes. In addition to being well-known in Jiangmen City, where the Gulao region of rivers and lakes is located, it is also less well-known in cities around Jiangmen such as Guangzhou and Foshan.

The main reason is that Gulao region of rivers and lakes has not established its own integrated media matrix and the content communication platforms are scattered. Although it may gain greater popularity in the short term, it is not conducive to the long-term cultivation of high loyalty audiences and overall brand image. Taking the live broadcasts of scenic activities as examples, there are four live broadcasts planned by the official participation of Gulao region of rivers and lakes. The live broadcast platforms are the CCTV News Weibo account, the Heshan Convergence Media Live Room, the "Most-Heshan" APP and the "One Shenzhen" APP. The four live broadcasts used four platforms, and the connection between the platforms and the connection between the platforms and the Gulao region of rivers and lakes is weak, which is not conducive to the cultivation of the brand communication platform's sense of depth and the accumulation of platform fans. At the same time, the latter three platforms are all regional live broadcast platforms, which limit the scope of influence of brand communication, resulting in low brand awareness of "China Gulao".

\subsection{Communication Content Is Homogenizated, and Brand Recognition Is Low}

Surrounded by a unique hydrological environment, the Gulao Water Town has nurtured a rich and characteristic water culture in the long years. There are mainly celebrity cultures based on Wang Laoji and Huang Baiming, and a food culture based on fish skin corners and other cuisines of region of rivers and lakes, the Wing Chun culture represented by Ryazan Wing Chun, and the folk culture represented by "Racing Dragon Boat at the Region of Triply Wood Bridge". However, at this stage, the degree of transformation from the regional culture of the Gulao region of rivers and lakes to cultural brands is low, and cultural brands such as Wing Chun and Dragon Boat Racing have the problems of homogeneity of cultural tourism products and low brand recognition.

After taking over the Gulao region of rivers and lakes, the OCT Group registered the "Jiangmen Overseas Chinese Town" and "Gulao Water Township" public accounts to deliver brand 
information, and created \#漫寻古劳\# (searching for Gulao) and \#华侨城古劳水乡\# (OCT Gulao region of rivers and lakes) topics on Douyin to integrate KOL resources and UGC content, to control the direction and quality of brand communication content. However, the content is mainly about scenery introduction and play strategy, focusing on the beautiful scenery of lotus pond and Wing Chun culture. The content is homogenized. There are few introductions to the unique folk culture and food culture of Gulao region of rivers and lakes, and it also failed to make full use of the "Dragon Boat Race", "Wing Chun Cultural Festival" and other festival tourism resources for brand communication, and did not have an advantage in competition with brands such as Sanshui Lotus World and Foshan Wing Chun.

In the survey and analysis of the changes in the audience's perception of brand image, the interviewees' perceptions of the characteristics of scenic spots in Gulao region of rivers and lakes are still generally vague, and both the willingness to consume and the willingness to preferential choice have declined to a certain extent, and the degree of recognition of the brand's cost-effectiveness has also decreased. The demand map from the keyword search also shows that consumers are more inclined to combine the Gulao region of rivers and lakes with other scenic spots when making short-distance travel plans instead of in-depth visits.

It can be seen that although the tourist projects in Gulao region of rivers and lakes are gradually enriched at this stage, the information and brand image embodied by the brand in the process of communication lack unique memory points, fail to resonate with the audience, nor don't they meet the expectations of consumers' travel experience.

\section{OPTIMIZING STRATEGY OF CULTURAL TOURISM BRAND COMMUNICATION IN GULAO REGION OF RIVERS AND LAKES}

\subsection{Building and Improving a Financial Media Matrix That Reflects Brand Characteristics}

\subsubsection{Creating Brand Anthropomorphic Accounts and Building a Media Interactive Discourse System with Brand Personality}

The anthropomorphic brand interactive discourse system can extend the target audience to a wider potential audience group and make up for the lack of coverage in offline scenic spots. "Mr. Zan" brand accounts were created in Bilibili, Xiaohongshu, Weibo and Sohu, and the model is based on Ryazan, the master of Wing Chun, combined with the current brand positioning of "free" and "life in the region of rivers and lakes", it has formed a discourse system with a distinct personality, interacting with the audience in a relaxed and humorous tone. The increase of audiences at different levels has also promoted the expansion of the content level of Gulao region of rivers and lakes, which has enhanced the value of the brand itself.

\subsubsection{Creating Public-facing Accounts on Multiple Platforms to Increase Brand Temperature}

Official accounts are created on the four platforms of Zhihu, Toutiao, Yidian Information, and Baijiahao, and columns are set up to tell the public the brand story of "Chinese Gulao", such as the folklore of Mr. Ryazan, the Gulao region of rivers and lakes and the origin of Wang Laoji herbal tea, Gulao folk songs, etc., to strengthen the reputation of Gulao region of rivers and lakes in the field of humanities and social sciences, raise the temperature of the brand, and strengthen the sense of brand depth.

\subsubsection{Developing Cultural and Creative Products and Unblocking Online Sales Channels}

It is necessary to develop cultural and creative products that are popular with customers and have market competitiveness [5], and sell them on Taobao flagship stores and mini program malls. The online sales platform is a window for consumers to understand and contact the brand. The concept of "free flowing country life in region of rivers and lakes" should always be run through the operation and promotion activities. In the shop page design, customer service, copywriting, etc., it must also be unified with the brand tone.

\subsubsection{Continuously Deepening the Network Penetration of Brand Communication}

In future brand communication activities, digital marketing is the main direction. It is necessary to 
strengthen cooperation with Internet platform KOLs, invite KOLs from different fields such as tourism, food, music and other fields to check in at the Gulao region of rivers and lakes, so as to produce communication content that can reflect the experience of different consumers, avoiding the situation where multiple bloggers use the same video material.

Secondly, with the help of brand cross-border marketing, keyword bidding ranking in search engines, online and offline linkage of festival tourism activities and other Internet marketing methods, big data technology can be used to accurately reach target consumer groups and increase brand exposure and influence. In terms of cross-border marketing, priority is given to cooperation with well-known local celebrities or brands in Gulao region of rivers and lakes, such as Wang Laoji Herbal Tea, through the form of brand anthropomorphic image frame, sales of co-branded products, UGC content production and other forms to carry out the cooperation.

\subsection{Strengthening the Awareness of Media Service, and Enriching Media Technology and Communication Content}

\subsubsection{Online Media Content \\ Communication Should Be Combined \\ with Advanced Internet Technology to \\ Increase Audience Involvement}

It is necessary to fully understand and analyze consumers' information needs and media usage habits. When communicating with fans and disseminating brand stories to the public, it will be of great influence to use "audio + 3D animation", "SVG + comics", "short message applet + 5G" and other technologically advanced, innovative, visual, audible, playable, and sensible innovative integrated media products to enrich the brand culture and products display forms, produce interactive dramas, audio comics, SVG interactive comics and other new media content based on the stories of Ryazan and other celebrities in the Gulao region of rivers and lakes to attract consumers to participate in the interaction, and rely on social media platforms to build a tourist community and promote the secondary communication of brand content.

\subsubsection{Continuously Improving Offline \\ Tourism Products and Enriching \\ Tourist Experience}

High-quality products are the foundation of brand building. Under the condition of fully understanding its own actual situation, it will be an advancement to apply the "Internet + cultural tourism" experience obtained by OCT Group in the practice of other tourism products to the digital transformation and upgrade of the operation and management model of Gulao region of rivers and lakes [6], change the previous extensive development model, optimize the tourist experience through media technologies such as interaction between tourists and virtual characters on the same screen, navigation of boutique tour routes, and realtime monitoring of the flow of people, and strengthen the connection between scenic spots and between scenic spots and tourists to meet consumers' demand for diversified and personalized tourism services.

\subsection{Making Full Use of Festival Tourism Resources to Create a Cultural Trend Towards Hot Topics}

In addition to making use of existing festival tourism resources such as "Dragon Boat Race" and Ryazan Wing Chun Cultural Festival, it can also combine current popular cultural elements and social hotspots to organize offline activities such as Shibanqiao Marathon and Wing Chun Quick Flashing. The secondary communication of derivative content such as interactive videos, content stalks, and B-site auto-tune remix-themed content videos can be used to increase brand exposure, thereby creating hot topics, allowing "China Gulao" to quickly attract social attention on social media, and then lead the flow to offline.

\subsection{Using Multi-party Behavior Image Design to Help Brand Media Image Upgrade}

Behavioral image design is the extension of concept design, and it is vividly called "the limbs of tourism culture brand image design", that is, the process of visualizing tourism concepts and finally internalizing them into tourism brand assets. The upgrade of the brand image of Gulao region of rivers and lakes not only needs to optimize and implement the behavioral image design of the government, tourism enterprises and residents in reality, but also requires a large number of high- 
quality interdisciplinary talents who understand both the media and the travel business. In the process of brand communication, the behavioral image display need to be integrated into media products and transformed into brand equity, and a full brand media image is necessary to be created in multiple dimensions to enhance consumer favorability.

\section{CONCLUSION}

The region of rivers and lakes is a unique geographical community in the Lingnan region, and also a "living museum" of regional culture. Under the guidance of the brand power strategy, cultural and tourism brand communication has received much attention as the most direct and effective means of communication of culture of region of rivers and lakes, and it is also one of the best means to take into account economic development and regional cultural protection. This article takes China's Gulao region of rivers and lakes as an example, discusses the important role of tourism brand communication in the new situation in the modernization of the regions of rivers and lakes, summarizes the current situation and existing problems of cultural tourism brand communication in Gulao region of rivers and lakes, and proposes optimization strategies to provide experience and reference for the transformation of cultural tourism brand assets of regions of rivers and lakes into economic development momentum.

\section{AUTHORS' CONTRIBUTIONS}

Yuting Li contributed to revising and editing and topic design, Baoer $\mathrm{Yi}$ is responsible for research design and wrote the manuscript.

\section{REFERENCES}

[1] Wang Rongde, Niu Ben, Qian Chenfei, Wu Xin, On the Path of Rural Revitalization in Coastal Developed Areas - Based on the Investigation and Analysis of Huzhou City in Zhejiang Province [J]. Journal of Huzhou Teachers College, 2020, 42(01): 1-7. (in Chinese)

[2] Kevin Lane Keller, Strategic Brand Management [M]. Li Naihe, Wu Jin, Zou Qi, etc. trans. Beijing: China Renmin University Press, 2014: 4. (in Chinese)

[3] Li Yinhuan, Long Xingxing. Oct Gulao Water Town Project phase I first opening area was launched, set sail to build China's most beautiful Lingnan region of rivers and lakes [N]. Jiangmen Daily, 2020-09-28(04). (in Chinese)

[4] Ma Youming, Li Mimi, Research on National Park Brand Image Measurement Model Based on Tourists' Perception [J]. Tourism Tribune, 2020, 13(04): 20-32. (in Chinese)

[5] Lu Lan. Research on Rural Tourism Development Based on Local Cultural Integration - A Case Study of Gulao region of rivers and lakes in Heshan [J]. Tourism Review (2nd half month), 2016(04): 112+114. (in Chinese)

[6] Oct Group Party Committee Publicity Department. Oct forges the high-quality cultural tourism engine based on the new development pattern $[\mathrm{J}]$. State-owned Assets Report, 2020(12): 72-74. (in Chinese) 